\title{
Agitation Effects and Kinetic Constants of Exoglucomannan Production by Antarctic Yeast Strain in a Stirred Tank Bioreactor
}

\author{
S. D. Vlaev, ${ }^{a,{ }^{*}}$ K. Pavlova, ${ }^{b}$ S. Rusinova-Videva, ${ }^{b}$ K. Georgieva, ${ }^{b}$ and D. Georgiev ${ }^{c}$ \\ anstitute of Chemical Engineering, Bulgarian Academy of Sciences, \\ Acad. G. Bonchev B1.103, 1113 Sofia, Bulgaria \\ 'Institute of Microbiology Lab of Applied Biotechnologies, \\ Bulgarian Academy of Sciences, \\ 139 Ruski Blvd, 4000, Plovdiv, Bulgaria \\ doi: 10.15255/CABEQ.2015.2276 \\ "Bourgas University "Prof. Dr. A. Zlatarov" \\ Chemical Engineering Department, \\ Original scientific paper \\ 1, Blvd. Prof. Yakimov, 8010 Bourgas, Bulgaria \\ Received: July 8, 2015 \\ Accepted: December 5, 2016
}

\begin{abstract}
Exoglucomannan production by Antarctic yeast Sporobolomyces salmonicolor AL is studied at semi-tech scale in a $5 \mathrm{~L}$ stirred tank bioreactor and the bioreaction kinetics is quantified. The organism's unconventional response to agitation is analyzed in terms of the agitation-induced mechanical stress. The yeast maximum production activity was observed at agitation rate $400 \mathrm{rpm}$ and conserved or decreased at further increase in mixing intensity. Referring to the relationship of cell growth and aeration intensity, the various production activity, oxygen availability and cell growth are considered as a starting point to elucidate the possible reasons for the anomaly. At suspicion of shear detrimental effect on the yeast cells, the hydrodynamic stress acting on cell particles is determined and the microorganism morphology at low and high mixing intensity is examined. Biological stability is registered and the agitation effect is attributed to depressed metabolic activity at the evolving dissolved oxygen tension rather than to direct effect of hydrodynamics. A kinetic model is proposed. The specific growth rate $\left(\mu, \mathrm{h}^{-1}\right)$ and growth-associated (g EPS g ${ }^{-1}$ cells), and non-growth associated ( $\mathrm{g} \mathrm{EPS} \mathrm{g}^{-1}$ cells $\mathrm{h}^{-1}$ ) production constants are determined and compared with reported estimates for similar reference EPS fermentations. The model and its parameters are determined in well-mixed cultures and could be upgraded further to account for mixing non-ideality and mass transfer in larger vessels.
\end{abstract}

Key words:

exoglucomannan, Sporobolomyces salmonicolor $\mathrm{Al}_{1}$, hydrodynamic stress, morphology, kinetic modeling

\section{Introduction}

Cold-adapted yeasts are an important source of novel chemicals of commercial value ${ }^{1}$. Among these chemicals, the production of exopolysaccharides (EPS) has been emphasized ${ }^{2}$. The variety of EPS properties is proportional to the specificity of their molecules built up by various monomer sugars and in various structures ${ }^{3}$. Some EPS-producing systems have been introduced as industrially import$a^{4} t^{4}$. Biotechnology for exoglucomannan production by cold-adapted Antarctic yeast aimed to improve the component balance of pharmaceutical cosmetics has been developed ${ }^{5}$. The bioproduct has been purified and examined as a component of cos-

"Corresponding author. Tel.: +359 28703273 ;

E-mail address: mixreac@gmail.com metic creams and the bioreaction has been put forward as practically important ${ }^{2}$. Considering knowledge on cold-adapted fermentations, a bioreactor optimal performance involving Antarctic strains and its analysis, in view of bioprocess extrapolation to a larger scale, is of interest to bioengineering.

Due to the specific origin of the cold-adapted cells, the engineering analysis is extended to cover the unconventional response of the microorganisms to operating conditions and its impact on the bioprocess kinetics. There is numerous evidence about the peculiar behavior of cold-adapted yeasts appearing as variable activity related to previous continuous adaption of the original species to the Antarctic environmental extremes ${ }^{6}$. Adaption to cold is often combined with adaption to other limiting conditions. Such adaptation has been termed as survival with low metabolic activity or as long period dormancy with or without reproduction accompanied 
by production of lipids, accumulation of anti-freeze proteins and synthesis of cold-adapted enzymes, tending at the extreme to reduced aerophylic properties and even to anaerobiosis ${ }^{6}$. For example of exoglucomannan production by Antarctic yeast, the specific behavior of cold-adapted Sporobolomyces salmonicolor $\mathrm{AL}_{1}$ has shown a decrease in the specific production rate corresponding to an increase of agitation intensity 5 . Related to oxygen availability, cell morphology and metabolic activity, the fact has raised controversy about the effect of agitation upon yeast cell performance. This is because mixing intensity affects oxygen availability, but also increases the hydrodynamic stress that might cause changes in cell morphology or cell physiological responses with effect on cell metabolism?

In spite of its importance, no comprehensive analysis of the specific cold-adapted cell response from the engineering viewpoint of bioprocess practical implementation has come to the authors' attention. Apart from cold-adapted microorganisms, the interaction between kinetic and mixing phenomena related to EPS production has been discussed in detail only by Galindo and coworkers ${ }^{8,9}$. Along with the problem referring to possible effect of hydrodynamic stress on cell morphology, the authors usually relate shear stress with specific input power of agitation. They avoid reporting explicitly the rate of deformation. However, the specific input power acting on cells is a volumetric average estimate, while the impact on the microorganisms is related to the velocity gradients near the cell surface. Consequently, the effect of hydrodynamic stress on cell morphology may be masked by the volumetric variable. A more exact analytical approach, e.g. based on shear flow simulation, would be beneficial for the understanding of the effect of agitation.

Referring to the bioprocess kinetics, so far kinetic analyses of EPS-producing systems have been introduced by Garcia-Ochoa et al. ${ }^{10}$ and Serrano-Carreon et al. ${ }^{8}$ concerning xanthan gum production, by Peňa et al. ${ }^{11}$ concerning production of alginate, and more recently by Cheng et $a l .{ }^{12}$ for pollulan, and Torres et al. ${ }^{13}$ regarding fucose-containing EPS. A kinetic model was used by Zhang et al. ${ }^{14}$ to study the synthetic characteristics of EPS. Except the study by Torres et al..$^{13}$ using a Monodtype equation, the authors employed the logistic model for biomass growth and the Luedeking-Piret model for biopolymer production. They all reported good predictability of the production time-course.

The aim of this paper is elucidation of the agitation-induced stress effect on exoglucomannan production by Antarctic yeast and evaluation of the bioprocess kinetics.

\section{Experimental}

\section{The strain}

The yeast strain Sporobolomyces salmonicolor $\mathrm{AL}_{1}$ was isolated from Antarctic soil in the region of the Bulgarian base on Livingston Island. It has been identified and registered in the National Bank for Industrial Microorganisms and Cell Culture, Bulgaria, entry N 8290.

\section{Bioreactor set-up and culture conditions}

The bioreactor was a dual impeller 5-L stirred vessel with diameter $T=0.16 \mathrm{~m}$ and impeller diameter $D=0.064 \mathrm{~m}$ (Sartorius Biostat A plus). Its working volume was $V_{R}=4.5 \mathrm{~L}$. It was equipped with two conventional six flat-blade turbines. Air was fed through a ring sparger. Oxygen and $\mathrm{pH}$ were controlled by probes (Hamilton, Bonaduz AG, Swiss made) immersed in the culture liquid. All operating parameters were monitored on-line (BioPAT ${ }^{\circledR M F C S / D A 3.0) . ~}$

The substrate was sucrose. In all runs, the fermentation medium contained $\left(\mathrm{g} \mathrm{L}^{-1}\right)$ : sucrose, 50; $\left(\mathrm{NH}_{4}\right)_{2} \mathrm{SO}_{4}, 2.5 ; \mathrm{KH}_{2} \mathrm{PO}_{4}, 1.0 ; \mathrm{MgSO}_{4} \cdot 7 \mathrm{H}_{2} \mathrm{O}, 0.5$; $\mathrm{NaCl}, 0.1 ; \mathrm{CaCl}_{2} \cdot 2 \mathrm{H}_{2} \mathrm{O}, 0.1$; and yeast extract, 1.0. The inoculum $(10 \% \mathrm{w} / \mathrm{v})$ was obtained in $500-\mathrm{mL}$ flasks containing $50 \mathrm{~mL}$ of Sabouraud medium (Merck, Germany). Batch fermentation for $96 \mathrm{~h}$ was carried out. High production of biologically active substances was obtained at $22{ }^{\circ} \mathrm{C}$ and $\mathrm{pH} 5.3$ coupled with aeration rate of $1 \mathrm{vvm}$. The apparent viscosity of the biofluid was measured by rheometer Rheotest 2 to approach $15 \mathrm{mPa}$ s at $400 \mathrm{rpm}$, the value corresponding to experimental consistency coefficient $K=0.02 \mathrm{~Pa} \mathrm{~s}^{\mathrm{n}}$ and flow index $n=0.78$ used in the calculations. Detailed descriptions of these measurements are reported elsewhere ${ }^{5}$.

\section{Measurement of product and biomass concentrations, and morphology study}

The experiments covered a range of impeller speeds between 100 and $600 \mathrm{rpm}$. The biomass was isolated from the culture medium by centrifugation at $5000 \mathrm{~g}$. The supernatant was treated with $96 \%$ ethanol to obtain the EPS. Details on the fermentation media and conditions have been reported in previous strain selection achievement experiments in flasks ${ }^{15}$. The biomass and the amount of yeast polysaccharide were determined by dry-weight measurements. The residual sugar concentration was measured by the Megazyme method (Sucrose/D-Fructose D-Glucose assay kit) K-SUFRG 12/05 (Megazyme International Ireland Limited, 2005, Wicklow, Ireland). 
Morphology was studied by scanning electron microscopy (SEM). SEM was performed ex-situ by microscope Lyra Tescan at acceleration voltage 30 $\mathrm{kV}$. In advance, the samples were fixed in $4 \%$ solution of glutaraldehyde in $0.1 \mathrm{~mol} \mathrm{~L}^{-1}$ sodium cacodylate buffer (SCB) pH 7.2 for $24 \mathrm{~h}$ at $0-4{ }^{\circ} \mathrm{C}$. Following triple rinse $(3 \times 15 \mathrm{~min})$ in $\mathrm{SCB}$ and post-fixation in $1 \% \mathrm{OsO}_{4}$ in $\mathrm{SCB}$ for $1 \mathrm{~h}$ at $0-4{ }^{\circ} \mathrm{C}$, the samples were dehydrated in ascending ethanol series, mounted on supports and gold-coated in vacuum evaporator Edwards Sputer Coater S150A ready for SEM.

\section{Bioreactor flow field analysis}

The flow field was studied by simulation. The hydrodynamic stress in various parts of the vessel was determined from shear rate data. Computational flow modeling CFD of the dual impeller batch mixing vessel was employed to generate the shear field. The two-phase Euler-Euler model was used with and without enabling the volume fraction equation to simulate gas presence or absence ${ }^{16-18}$. Turbulence was described by the two-equation standard $k-\varepsilon$ model coupled with the power law physical model of non-Newtonian flow for the fermentation media. For computational analysis, the commercial code Fluent (ANSYS FLUENT Release 13.0, ANSYS, Inc., 2010) was employed. The finite-volume solution technique was based on grid of approx. $5 \cdot 10^{5}$ cells. Model validity was checked by matching predicted gas volume fraction and strain rates with experimental hold-up and shear rate data at similar rotational speed. The spatial distribution of the flow variables, e.g. fluid linear velocity and hydrodynamic shear stress in and out of gas presence, were determined. The hydrodynamic stress $\tau$ was determined by the power law equation of the non-Newtonian bio-fluid $\tau=K \dot{S}^{n}$ using strain rate $\dot{S}=\frac{\partial V_{j}}{\partial x_{i}}+\frac{\partial V_{i}}{\partial x_{j}}$, as determined from the overall solution of the momentum conservation equation resolved by the fluid dynamic simulation $\operatorname{code}^{16}$. In these equations $K, n$, and $V$ stand for fluid consistency coefficient, flow index, and fluid linear velocity, respectively, and $x$ is the space coordinate. In the procedure, the culture fluid rheological constants, namely, $K=0.02 \mathrm{~Pa} \mathrm{~s}^{\mathrm{n}}, n=0.78$, were used.

\section{Kinetic characterization}

Unstructured model was proposed. Biomass growth was assumed to be represented by the logistic function ${ }^{19}$ and the maximum specific growth rate $\mu_{m}$ was determined by fitting experimental biomass data $x$ with the integrated linear form of the VerhulstPearl equation resolved for autocatalytic reaction ${ }^{20}$ :

$$
r_{x}=\frac{\mathrm{d} X}{\mathrm{~d} t}=\mu X=\mu_{m} X\left(1-\frac{X}{X_{m}}\right)
$$

resolved, as $F(X)=\ln \frac{X\left(1-\frac{X_{0}}{X_{m}}\right)}{X_{0}\left(1-\frac{X}{X_{m}}\right)}=\mu_{m} t$.

The value of $\mu_{m}$ was determined from this equation, as the slope of the line $F(X)$ versus time.

In this equation, $X$ is biomass concentration at any time during batch growth, and maximum specific growth rate $\mu_{m}$ and maximum biomass concentration $X_{m}$ at the end of batch growth are kinetic constants, and $X_{0}$ stands for initial biomass concentration at inoculation.

A Luedeking-Piret equation ${ }^{21}$ was proposed to describe product $P$ formation and the growth-associated (g EPS g ${ }^{-1}$ cells) and non-growth associated $\left(\mathrm{g}\right.$ EPS $\mathrm{g}^{-1}$ cells $\mathrm{h}^{-1}$ ) production yield of exoglucomannan have been accounted for by constants $\alpha$ and $\beta$, respectively:

$$
\frac{\mathrm{d} P}{\mathrm{~d} t}=\alpha \frac{\mathrm{d} X}{\mathrm{~d} t}+\beta X
$$

From the condition $\frac{\mathrm{d} X}{\mathrm{~d} t}=0$ corresponding to stationary growth, parameter $\beta$ could be determined as $\beta=\frac{\mathrm{d} P}{\mathrm{~d} t} / X_{m}$.

Knowing $\beta$, a trial and error procedure over the production equation (3) matching the experimental data was used to determine the growth-associated kinetic constant $\alpha$.

For the model equations (1) and (3) to be valid and the kinetic model constants to be evaluated, an invariable reaction mechanism relevant to sustainable cell morphology should be ensured.

\section{Oxygen uptake rate measurement}

Oxygen mass transfer analysis was carried out at reactive conditions. The value of OUR was determined by the unsteady stop-gassing measurement technique from the dissolved oxygen concentration depletion curve as $(\mathrm{d} O / \mathrm{d} t)_{r}$ following from the mass balance of dissolved oxygen with zero gas phase at gas flow interruption, and yeast respiration presence. The procedure of partial solution of the oxygen mass balance supported by the experimental program was followed as described by GarciaOchoa and Gomez ${ }^{22}$. 


\section{Results and discussion}

\section{Kinetics' agitation effects assessed by product concentration, cell growth, and DO}

Fig. 1 illustrates the maximum cell $X_{m}$ and product $P$ concentrations generated at low ${ }^{m}(100$ rpm) and high (400-600 rpm) impeller speed. The aeration rate in all cases was maintained at the high optimum level of $1 \mathrm{vvm}$ estimated previously to give stable production results ${ }^{15}$. Based also on previous runs ${ }^{5}$, the trend of cell concentration and EPS production decrease confirmed highest yields at moderate agitation, as well as conservation and decrease of cell activity at agitation rates exceeding $400 \mathrm{rpm}$

Fig. 2 shows the time-course of the yeast growth rate and confirms this effect.

Fig. 3 compares the dissolved oxygen (DO) concentration curves corresponding to various mixing intensities. The relevant yeast oxygen uptake rates (OUR) are indicated as a tabulated attachment. While the regime of low mixing intensity $(100 \mathrm{rpm})$ is clearly not desirable because of insufficient oxygen supply to the cells, the other three regimes allow oxygen-unlimited growth. Yet, different respiration and oxygen uptake is registered and seen to decrease significantly with impeller speed. Oxygen availability is high but the dissolved oxygen at high mixing intensity is not consumed. The decreasing OURs corresponding to the ever increasing mixing intensity could be interpreted as yeast decreasing activity.

Were this agitation effect due to changes in morphology caused by the mixing-induced hydrodynamic stress or were it due to inherent specific metabolism of cold-adapted microorganisms, the flow field of agitation-induced hydrodynamic stress and the corresponding yeast morphology were examined as an answer to the quest.

\section{Hydrodynamic stress and morphology data}

The bioreactor flow field was simulated and the hydrodynamic shear rate $(\dot{S})$ corresponding to the regimes of low (100 rpm) and high mixing intensity $(400 \mathrm{rpm})$ was assessed. Both the inner flow shear and the shear at solid-fluid interfaces, i.e. impeller blades and sparger pipe, were determined. The geometry of the bioreactor is shown in Fig. 4(a), and the corresponding shear rate contour plots on the impeller blade and sparger walls are plotted in Fig. 4(b). Based on the CFD flow field results point values, the maximum $\left(\dot{S}_{m}\right)$ and area-average $(\dot{S})$ shear rates at the impeller-fluid interface and in the inner fluid $\left(\dot{S}_{\text {fluid }}\right)$ are determined and plotted in Fig. 5. The shear stress $\tau$ corresponding to the $\dot{S}$-values is determined and accounted for on the

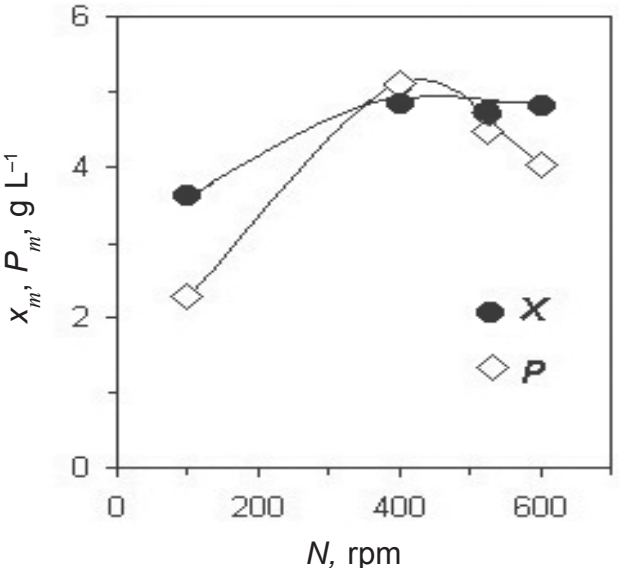

Fig. 1 - Biomass and exoglucomannan yields at various mixing intensities

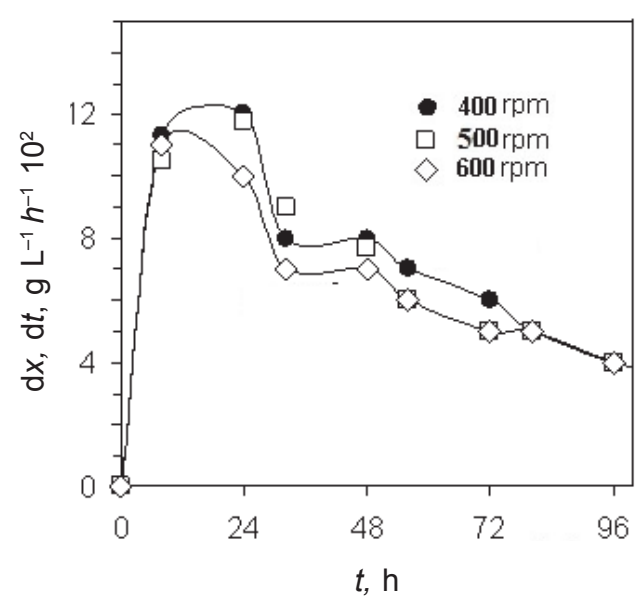

Fig. 2 - Time course of the yeast growth rate at various mixing intensities

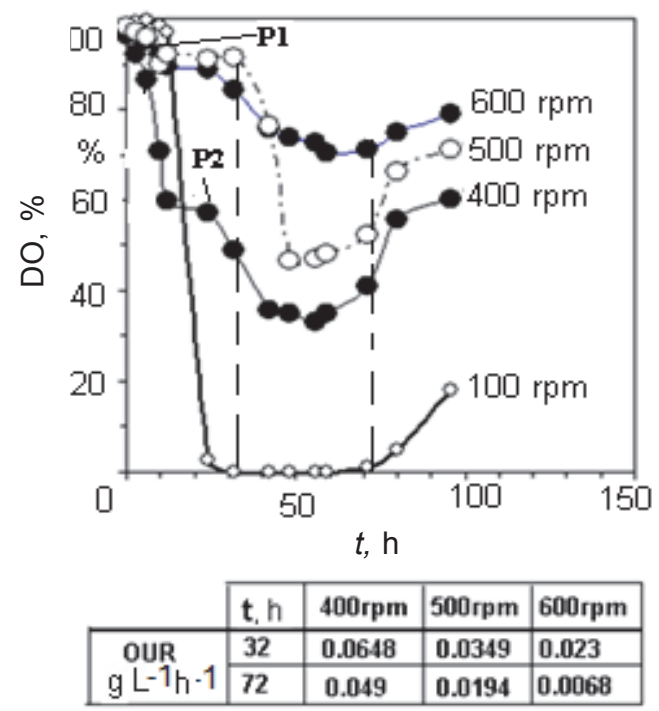

Fig. 3 - Kinetic dissolved oxygen concentration (DOC) curves with indicated yeast oxygen uptake rates (OUR) corresponding to the 32nd and 72nd hour of bioreaction 

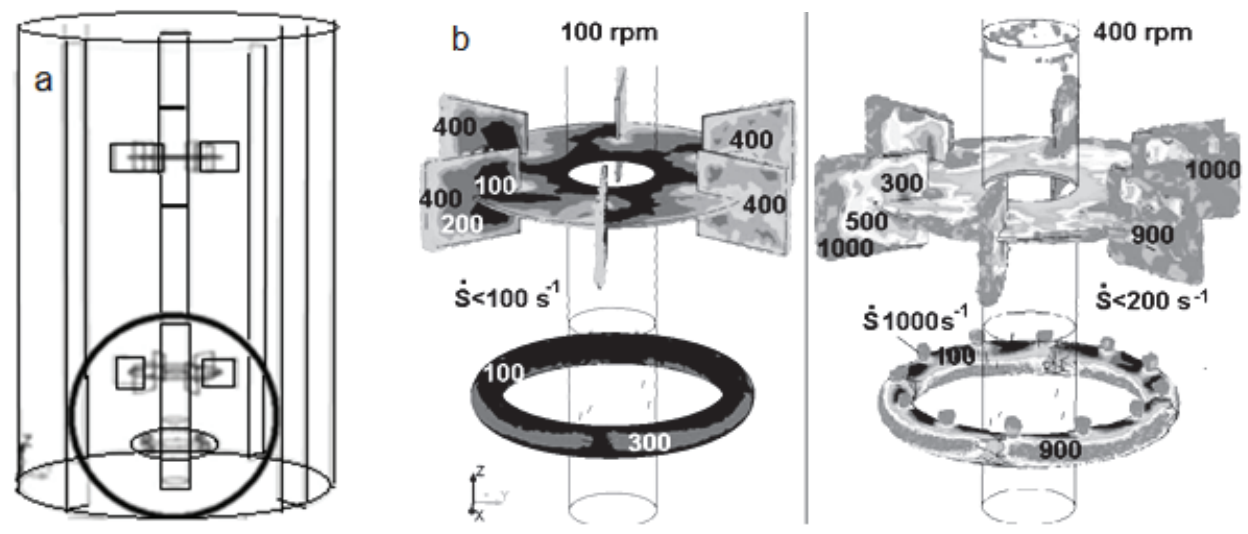

Fig. 4 - Bioreactor schematic (a) and typical shear rate values corresponding to the impellerfluid interface and the fluid (b)

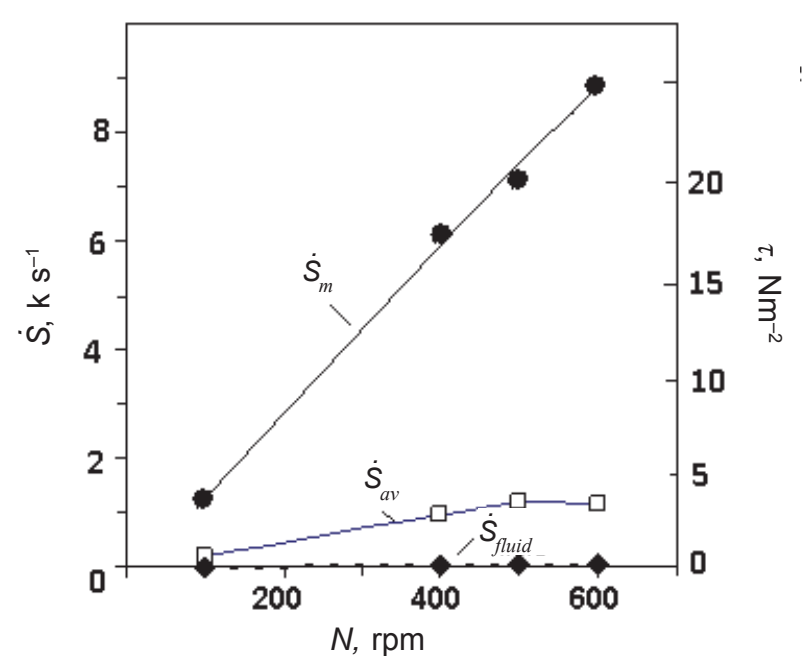

Fig. 5 - Impeller shear rate maximum $\dot{S}_{m}$ and average $\dot{S}_{a v}$ values, and fluid average shear rate $\dot{S}_{\text {fluid }}$ versus impeller speed

right hand side vertical axis. One could see that, by increasing impeller revolutions four times between 100 and $400 \mathrm{rpm}$, the shear rate at the solid interfaces increased up to 10 -fold from $10^{2} \mathrm{~s}^{-1}$ to $10^{3} \mathrm{~s}^{-1}$, the maximum strain exceeding $6000 \mathrm{~s}^{-1}$.

Yeasts propagate by budding and it has been shown that budding yeast cells can be damaged by mechanical stress resulting from agitation of the culture $^{7}$. In view of the fact that shear rate of 1000 $\mathrm{s}^{-1}$ in the particular culture (i.e. $K$ and $n$ ) may impose shear stress exceeding $4 \mathrm{~N} \mathrm{~m}^{-2}$, and that such force has been shown to present a potential risk to cell viability ${ }^{7,23}$, the yeast morphology was examined.

The effect of shear stress on the biological immutability of Sporobolomyces salmonicolor $\mathrm{AL}_{1}$ has been sought by changing agitation speed from low $120 \mathrm{rpm}$ to optimum $400 \mathrm{rpm}$, corresponding to impeller shear stress rise from $4 \mathrm{~N} \mathrm{~m}^{-2}$ to $17 \mathrm{~N} \mathrm{~m}^{-2}$. In both cases, morphology patterns were shot in two different points of growth, namely in the 8th (P1) and 24th (P2) hour of fermentation, corresponding to a sharp jump in oxygen consumption related to intensive cell division and growth of yeast cells, as seen in the DO profile in Fig. 3. Fig. 6 contains the results. It represents a summary of 20 scanned micrographs of the two mixing regimes, e.g. the one that was expected to produce well, and a pattern at low mixing intensity. For example, Figs. 6(a) and 6(b) correspond to the 8th and the 24th hour of fermentation at $120 \mathrm{rpm}$; alternatively Figs. 6(c) and 6(d) correspond to similar time at $400 \mathrm{rpm}$. The micrographs visualize the yeast cells with the teliospores (ts), the basidia (b), and the ballistospores (bs) indicated. Extracellular mass of polysaccharide is seen as amorphous sections marked by asterisks predominantly in the high-intensity mixing regime, where the bioreaction is rigorous and the product is accumulated. The cells in the early hour of fermentation (a) and (c) exhibit a slightly ridged middle surface that is smoothening in parallel to advanced fermentation as expected. The micrographs assigned to larger mixing speed showed homogeneous biomass of oval cells accumulating EPS, which conforms to the more uniform dispersion of oxygen and lack of DO limitation corresponding to this operational regime. Similar structures showing no break up or change in the development of morphology are seen in both mixing regimes at low and high mixing intensity. Apart from the appearance of the amorphous zones of the product EPS, no significant difference in the pattern occurred due to agitation rise or corresponding hydrodynamic stress in the problem areas of the impeller and the sparger. Since no evidence of the hydrodynamic stress effect is observed, and as oxygen availability is increasing with agitation rate accompanied by respiration decline, a change in the physiological response towards the increased dissolved oxygen tension leading to depressed activity is proposed to explain the bioreaction delay and decline at high rates of agitation. 


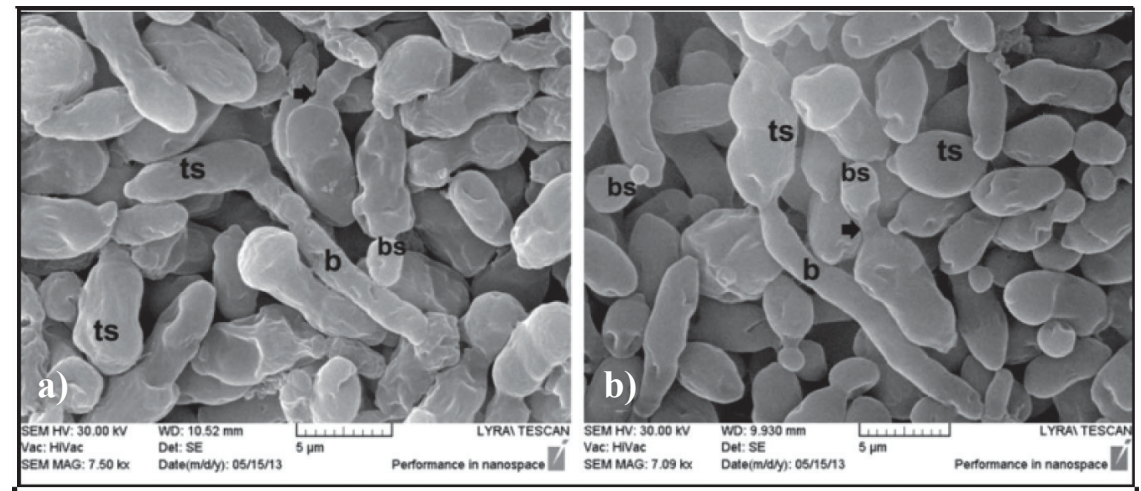

$N=100 \mathrm{rpm}, \tau=4.37 \mathrm{~N} \mathrm{~m}^{-2}$

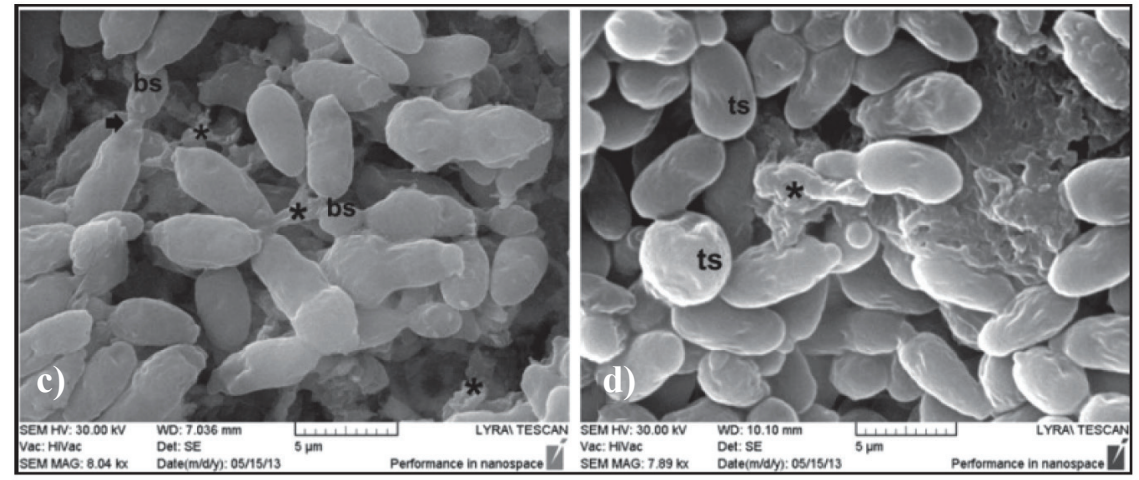

$N=400 \mathrm{rpm}, \tau=17.7 \mathrm{~N} \mathrm{~m}^{-2}$

Fig. 6 - Yeast Sporobolomyces salmonicolor AL, morphology vs. growth stage and mixing intensity: $a, b$ corr. to $8 \mathrm{~h}$ and $24 \mathrm{~h}$ at mixing intensity $120 \mathrm{rpm} ; \mathrm{c}, d$ corr. to $8 \mathrm{~h}$ and $24 \mathrm{~h}$ at mixing intensity $400 \mathrm{rpm}$

Nevertheless, the results in Figs. 1-6 confirmed relevance of the mixing regime of moderate agitation as appropriate for exoglucomannan production and this regime was perceived for modeling.

\section{Bioprocess kinetic parameters}

The kinetic model (1)-(3) was employed. From the kinetic data concerning biomass growth, $\mu_{m}$ could be determined from the slope of the line described by Eq. (2): $\mu_{m}=0.0563 \mathrm{~h}^{-1}$. Since $X_{m}=4.8$ $\mathrm{g} \mathrm{dm}^{-3}$, the specific growth rate $\mu$ is represented explicitly by the equation: $\mu=0.056\left(1-\frac{X}{4.8}\right)$. From the production $\mathrm{d} P / \mathrm{d} t v s$. time curve, the mean production rate in the stationary stage was determined as $0.02 \mathrm{~g} \mathrm{~L}^{-1}$ per hour and the non-growth-associated production constant $\beta=0.004$ (g EPS g $^{-1}$ biomass $\left.\mathrm{h}^{-1}\right)$. Differentiating the experimental EPS concentration data versus time, and interpolating using equation (2) with known $\beta$ and $X_{m}$ values, parameter $\alpha=1.2 \mathrm{~g} \mathrm{EPS} \mathrm{g}^{-1}$ biomass was found by curve fitting.

Table 1 - Kinetic constants of EPS production by various cultures

\begin{tabular}{c|c|c|c|c}
\hline Parameters & $\begin{array}{c}\text { This work } \\
\text { (Glucomannan, } \\
\text { Sporobolomyces } \\
\left.\text { salmonicolor } \mathrm{A}_{1}\right)\end{array}$ & $\begin{array}{c}\text { Garcia-Ochoa et al. } \\
(1995)^{10} \\
\text { (Xanthan gum, } \\
\text { Xanthomonas campestris) }\end{array}$ & $\begin{array}{c}\text { Serrano-Carreon } \text { et al. } \\
(1998)^{8} \\
\text { (Xanthan gum, } \\
\text { Xanthomonas campestris) }\end{array}$ & $\begin{array}{c}\text { Pena et al. }(2000)^{11} \\
(\text { Alginate, } \\
\text { Azobacter vinelandii) }\end{array}$ \\
\hline$\mu_{m}\left(\mathrm{~h}^{-1}\right)$ & 0.056 & 0.11 & 0.25 & 0.2 \\
$X_{0}\left(\mathrm{~g} \mathrm{~L}^{-1}\right)$ & 0.5 & 0.04 & 0.05 & - \\
$X_{m}\left(\mathrm{~g} \mathrm{~L}^{-1}\right)$ & 4.8 & 1.79 & 4.42 & 4.6 \\
$\alpha\left(\mathrm{g} \mathrm{EPS} \mathrm{g}^{-1}\right.$ biomass) & 1.2 & 10.3 & 2 & 0.48 \\
$\beta\left(\mathrm{g} \mathrm{EPS} \mathrm{g}^{-1}\right.$ biomass $\left.{ }^{-1}\right)$ & 0.004 & 0.003 & 0.25 & 0.06 \\
\hline
\end{tabular}



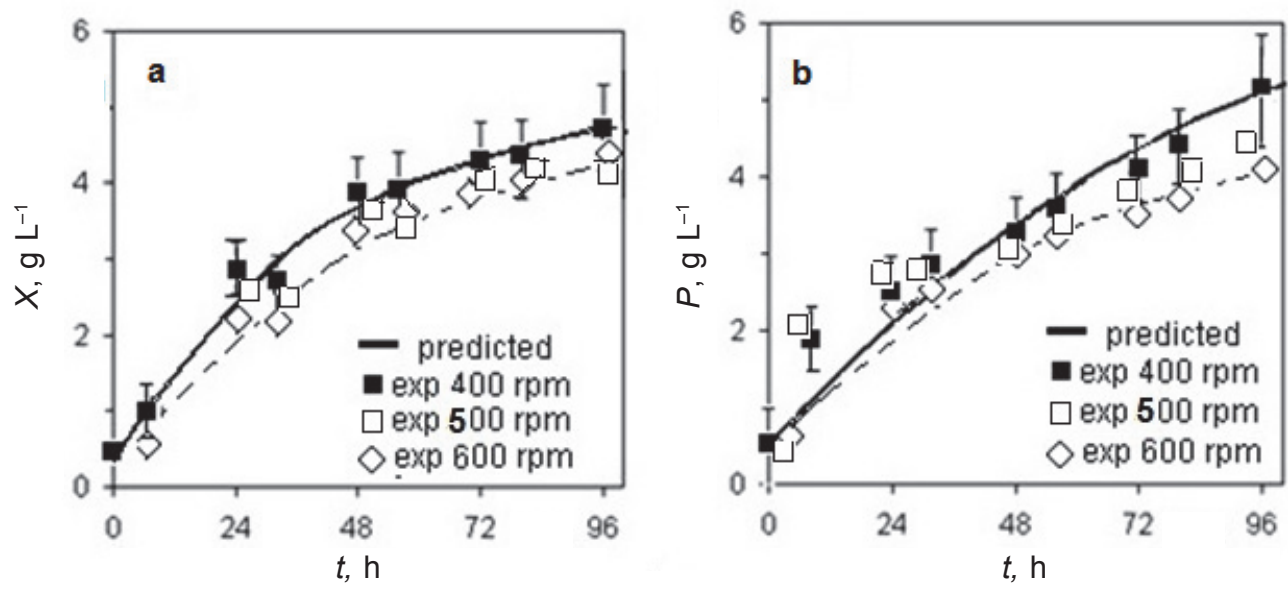

Fig. 7 - Experimental (points) and simulated data (solid lines) for EPS production by Antarctic yeast strain Sporobolomyces salmonicolor $A L_{1}$ : biomass (a) and exoglucomannan (b) production curves

Example model predictions and experimental bioreaction evolution data at $400 \mathrm{rpm}$ corresponding to optimal performance and the experimental data at 500 and $600 \mathrm{rpm}$ are compared in Figs. 7(a) and 7(b). One could infer that the predictability of biomass and EPS concentrations in time are accurate enough to allow the use of the kinetic model for process simulation.

Table 1 compares the values of the kinetic parameters obtained for simulation of the glucomannan fermentation of this study with kinetic data reported for other EPS-producing systems using similar models. As seen in Table 1, the maximum specific growth rate obtained, namely, $0.056 \mathrm{~h}^{-1} \approx$ $0.1 \mathrm{~h}^{-1}$, is comparable with the data describing biomass production in the bacterial xanthan gum and alginate bioprocess. Compared to the bioprocess for alginate, the higher $\alpha$ is in favor of the mechanism of EPS production during microbial growth. Comparing $\alpha$ and $\beta$, all cases show prevalence of growth-associated production; this case has been reported as frequent performance at operation without $\mathrm{pH}$ control $^{8}$.

\section{Conclusion}

A bioprocess by cold-adapted Antarctic yeast Sporobolomyces salmonicolor $\mathrm{AL}_{1}$, reported as an important source of novel EPS, is examined and the effect of the agitation-induced hydrodynamic stress on the growth rate and EPS production rate is analyzed. Evidence is given to explain that the unconventional delay of bioreaction rate to agitation speed rise is not caused by changes in morphology. The adaptive mechanism of the yeast cells inherent from their Antarctic background supports a proposed explanation of the effect by physiological response accompanied by a decrease in metabolic activity at the evolving dissolved oxygen. A Luedeking-Piret kinetic model is proposed and the bioreaction kinetic constants corresponding to the regime of maximum activity of Sporobolomyces salmonicolor $\mathrm{AL}_{1}$ for EPS production are determined. They conform to prevailing growth-associated EPS production. The model equations are developed in well-mixed cultures and could be upgraded further to account for mixing non-ideality and mass transfer in larger vessels.

\section{ACKNOWLEDGEMENT}

The authors acknowledge the support of the National Research Fund of Bulgaria via grant DTK-02/46.

\section{List of symbols and abbreviations}

K $\quad-$ Consistency coefficient, Pa $\mathrm{s}^{\mathrm{n}}$

$N \quad$ - Impeller rotational speed, rpm

$n \quad-$ Flow index, dimensionless

$P \quad-$ EPS product concentration, $\mathrm{g} \mathrm{L}^{-1}$

$\dot{S} \quad-$ Shear/strain rate, $\mathrm{s}^{-1}$

$t \quad-$ Time, h

X $\quad$ - Biomass concentration, $\mathrm{g} \mathrm{L}^{-1}$

$x \quad-$ Space coordinate, $\mathrm{L}$

$\mathrm{d} P / \mathrm{d} t$ - Rate of change in product concentration, $\mathrm{g} \mathrm{L}^{-1} \mathrm{~h}^{-1}$

$\mathrm{d} X / \mathrm{d} t \quad$ - Growth rate, $\mathrm{g} \mathrm{L}^{-1} \mathrm{~h}^{-1}$

\section{Greek symbols}

$\alpha \quad-$ Growth-associated constant in LuedekingPiret model, g product $\mathrm{g}^{-1}$ biomass 
$\beta \quad-$ Non-growth-associated constant in Luedeking-Piret model, g product $\mathrm{g}^{-1}$ biomass $\mathrm{h}^{-1}$

$\mu_{m} \quad-$ Maximum specific growth rate, $\mathrm{h}^{-1}$

$\tau \quad-$ Shear stress, $\mathrm{N} \mathrm{m}^{-2}$

\section{Abbreviations}

CFD - Computational fluid dynamics

DO - Dissolved oxygen

EPS - Extracellular polysaccharide

OUR - Oxygen uptake rate

\section{References}

1. Buzzini, B., Vaughan-Martini, A., Yeast Biodiversity and Biotechnology, in Rosa, C. A., Peter, P. (Eds.), Biodiversity and Ecophysiology of Yeasts, Springer, Berlin, 2006, pp 533-559.

doi: https://doi.org/10.1007/3-540-30985-3_22

2. Pavlova, K., Production of polymers and other compounds of industrial importance by cold-adapted yeasts, in Buzzini, P., Margesin, R. (Eds.), Cold-Adapted Yeasts: Biodiversity, Adaptation Strategies and Biotechnological Significance, Springer, Berlin, Heidelberg, 2014, pp 397-415. doi: https://doi.org/10.1007/978-3-662-45759-7_18

3. Kumar, A. S. Mody, K., Microbial Exopolysaccharides: Variety and Potential Applications, in Rehm, L. H. A. (Ed.), Microbial Production of Biopolymers and Polymer Precursors: Applications and Perspectives, Caister Academic Press, 2009, pp 229-232.

4. Donot, F., Fontana, A., Baccou, J. C., Schorr-Galindo, S., Microbial exopolysaccharides: Main examples of synthesis, excretion, genetics, and extraction, Carbohyd. Polym. 87 (2012) 951

doi: https://doi.org/10.1016/j.carbpol.2011.08.083

5. Vlaev, S. D., Rusinova-Videva, S., Pavlova, K., Kuncheva, M., Panchev, I., Dobreva, S., Submerged culture process for biomass and exopolysaccharide production by Antarctic yeast: Some engineering considerations, Appl. Microbiol. Biotechnol. 97 (2013) 5303. doi: https://doi.org/10.1007/s00253-013-4864-3

6. Buzzini, B., Margesin, R., Adaption of Yeasts to Cold, in Buzzini, P., Margesin, R. (Eds.), Cold-Adapted yeasts: Biodiversity, Adaptation Strategies and Biotechnological Significance, Springer, Berlin, Heidelberg, 2014, pp 12-16.

7. Thomas, C. R., Problems of shear in biotechnology, in Winkler, M. A. (Ed.), Chemical Engineering Problems in Biotechnology, Springer, Berlin, 1990, p. 64-65.

8. Serrano-Carreon, L., Corona, R. M., Sanchez A., Galindo, $E$., Prediction of xanthan fermentation development by a model linking kinetics, power drawn and mixing, Process Biochem. 33 (1998) 133. doi: https://doi.org/10.1016/S0032-9592(97)00039-3

9. Tinoco-Valencia, R., Gomez-Cruz, C., Galindo, E., Serrano-Carreon, L., Toward an understanding of the effects of agitation and aeration on growth and laccases production by Pleurotus, J. Biotechnology 177 (2014) 67. doi: https://doi.org/10.1016/j.jbiotec.2014.02.013
10. Garcia-Ochoa, F., Santos, V. E., Alen, A., Xanthan gum production: An unstructured kinetic model, Enzyme Microb. Technol. 17 (1995) 206. doi: https://doi.org/10.1016/0141-0229(94)00009-G

11. Pen̆a, C., Trujillo-Roldan, M. A., Galindo E., Influence of dissolved oxygen tension and agitation rate on alginate production and its molecular weight in cultures of Azotobacter vinelandii, Enzyme Microb. Technol. 27 (2000) 390. doi: https://doi.org/10.1016/S0141-0229(00)00221-0

12. Cheng, K.-Ch., Demirci, A., Catchmark, G. M., Virendra, Z., Puri, M., Modeling of pollulan fermentation by using a color variant strain of Aureobasidium pollulans, J. Food Eng. 98 (2010) 353. doi: https://doi.org/10.1016/j.jfoodeng.2010.01.011

13. Torres, C. A. V., Marques, R., Antunes, S., Alves, V. D., Sousa, I., Ramos, R. M., Oliveira, R., Freitas, F., Reis, M. A. $M$., Kinetics of production and characterization of the fucose-containing exopolysaccharide from Enterobacter A47, J. Biotechnology 156 (2011) 261. doi: https://doi.org/10.1016/j.jbiotec.2011.06.024

14. Zhang, J.-G., Chen, X.-M. , He, X.-S., A study on the synthetic characteristics of the extracellular polysaccharide (EPS) of Ganoderma lucidum cultured in batch fermentation using a kinetic model original, Chinese J. Biotechnol. 23 (2007) 1065 doi: https://doi.org/10.1016/S1872-2075(07)60064-8

15. Pavlova, K., Koleva, L., Kratchanova, M., Panchev, I., Production and characterization of an exopolysaccharide by yeast, World J. Microbiol. Biotechnol. 20 (2004) 435. doi: https://doi.org/10.1023/B:WIBI.0000033068.45655.2a

16. Ranade, V. V., Computational Flow Modeling for Chemical Reactor Engineering, Academic Press, San Diego, 2003, pp 68-75; 12-104.

17. Ferziger, J. H., Peric, M., Computational Methods for Fluid Dynamics, Springer, Berlin, 1996. doi: https://doi.org/10.1007/978-3-642-97651-3

18. Vlaev, S. D., Staykov, P., Fialova, M., CFD - facilitated prognosis of bubble bed bioreactor performance based on bubble swarms oscillation analysis, Chem. Biochem. Eng. Q. 23 (2009) 513.

19. Kargi, F., Reinterpretation of the logistic equation for batch microbial growth in relation to Monod kinetics, Lett. Appl. Microbiol 48 (2009) 398. doi: https://doi.org/10.1111/j.1472-765X.2008.02537.x

20. Batuner, L. M., Posin, M. E., Mathematical Methods in Chemical Engineering, Chimia, S. Petersburg, 1971 pp 50-52 (in Russian).

21. Luedeking, R., Piret, E. L., A kinetic study of the lactic acid fermentation: batch process at controlled $\mathrm{pH}$, J. Biochem. Microbiol. Technol. Eng. 1 (1959) 393. doi: https://doi.org/10.1002/jbmte.390010406

22. Garcia-Ochoa, F., Gomez, E., Santosa, V. E., Merchuk, J. $C$., Oxygen uptake rate in microbial processes: An overview, Biochem. Eng. J. 49 (2010) 289. doi: https://doi.org/10.1016/j.bej.2010.01.011

23. Ludwig, A., Kretzmer, G., Shear stress induced variation of cell condition and productivity, J. Biotechnology 27 (1993) 217. doi: https://doi.org/10.1016/0168-1656(93)90110-9 